\title{
DIÁLOGO INTERNO COMO FUENTE DE AMBIVALENGIA EN MATEO ALEMÁN
}

En las últimas dos décadas la tradicional caracterización del GdA como "una novela cerrada, didáctica, una novela ejemplar en 8. realismo dogmático de desengaño", regida por una "voluntad vitalista monolineal"', ha perdido notablemente vigencia, y ha sido dejada de lado por conducir a una interpretación unívoca y monovalente tanto de la figura del personaje principal, a quien F. Rico describe en su calidad de non simplex natura ${ }^{3}$ como de la significación global del texto ${ }^{4}$. Desde posiciones más diversas, se señala ahora la ambivalencia y aun la ambigüedad del texto del $G d A$, bien en relación con el efecto del pluriestilismo o de la pluralidad discursiva hábilmente administrados por Alemán, bien como producto de su intencionalidad autorial, relacionada con su "capacidad de problematizar la realidad cotidiana" 5 . En cierta forma se puede decir que esta clase de complejidad conceptual y expresiva, por fin advertida en Alemán y descubierta por las vías más heterogéneas, despierta una fascinación por la figura y la obra alemaniana desconocida para la crítica de antaño, cuyo formidable ejemplo puede ser don Américo Castro, quien, al reconocer que "la novela moderna nació como una contienda entre un yo y otro yo, no entre situaciones, o entre bondades y p. 328.

C. Blanco Aguinaga, "Cervantes y la picaresca", NRFH, 11 (1957),

${ }^{2}$ J. C. Ghiano, "Actitudes humanas y literarias. Alemán y Cervantes", CuA, 8 (1949), p. 192.

${ }^{3}$ En su edición: Guzmán de Alfarache, Planeta, Barcelona, 1983, p. 19.

4 "No tan dogmático como se ha dicho, el autor ha implantado la ambigüedad en el centro de su obra, abandonándola en libertad a su propio juego" (F. Márquez Villanueva, "Sobre el lanzamiento y recepción del GdA", B'Hi, 92, 1991, p. 561).

${ }^{5}$ F. Rico, ed. cit., p. 36. 
maldades, o entre ansias de amor, bien o mal correspondido, etc.", concluye que "Mateo Alemán prorrumpió en un monumental monólogo"'6. Los trabajos de E. Cros, de F. Márquez Villanueva y de $\mathrm{F}$. Rico han abierto una brecha en el imponente monumento monologístico de la crítica tradicional alemaniana, que a menudo se reducía a la interpretación de El Pícaro en el sentido de una apología post-tridentina del catolicismo ${ }^{7}$, o como una estructura todavía medieval basada en el exemplum.

Por otra parte, no es menos fascinante advertir el potencial dialogizante del GdA, libro capaz de producir incluse ahora, a casi cuatrocientos años de haber salido a la luz, opiniones tan encontradas, que resultan mutuamente excluyentes. En lo que a interpretaciones gfobales conciome, estas divergencias pueden agruparse como mínmo en dos apartados opuestos. Uno de ellos estaría representado por algunas investigaciones ya no tan recientes, pero seminales, de $\mathrm{E}$. $\mathrm{Cros}^{8}$, así como por las de $\mathrm{F}$. Márquez Villanueva ${ }^{9}$, quienes descubren en la intencionalidad del discurso alemaniano una profunda veta de reformismo social, inseparable de un propósito laico moral. Otro apartado aparece ejemplificado por B. Brancaforte ${ }^{10}$, quien mediante una interpretación psicológico-discursiva explica al personaje de Guzmán como una metáfora de Sísifo, llegando a parangonar su complejidad con la del "hombre del subsuelo" de Dostoievski; esta línea subraya la inquietante y subversiva entonación en la rencorosa voz del pícaro. A la misma línea, creo, pueden adjudicarse otros trabajos de E. Cros, en los cuales este autor, al aplicar al discurso de Alemán los criterios semiológicos y sociocríticos, descubre una profunda y contradictoria asimilación del discurso represivo de la Inquisición en la misma exposición de los pecados de Guzmán al juicio del lector y en la propia autoconciencia del

${ }^{6}$ Cervantes y los casticismos españoles, Alfaguara, Barcelona, 1966, p. 82.

7 Cf. E. Moreno BáEZ, Lección y sentido del "GdA", Anejo XL de RFE, Madrid, 1948.

${ }^{8}$ Cf. por ejemplo Mateo Alemán. Introducción a su vida y obra, Anaya, Salamanca, 1971. Por otra parte, a E. Cros se le reconoce la primacía del descubrimiento detallado de la naturaleza proteica de GdA (Protée et le Gueux, Didier, Paris, 1967), empresa que lo sitúa entre los pioneros en tratar la complejidad guzmaniana.

${ }^{9}$ F. Márquez Villanueva, "Sobre el lanzamiento...", p. 561.

${ }^{10}$ Guzmán de 'Alfarache, ed. B. Brancaforte, Cátedra, Madrid, 1980, t. 1. pp. 13-51. 
personaje $\mathrm{e}^{11}$. Los calificativos tales como "pseudo-confesión"12, "vida no fidedigna y marañada"13, o de "burla"14, aplicados al $G d A$ se introducen en otros estudios, que analizan el discurso de Alemán desde el supuesto de la no veridicción.

Así pues, si F. Márquez Villanueva defiende el objetivo moral del libro, reconociendo en Alemán a un reformador social en ciernes ${ }^{15}$, inspirado en Cristóbal Pérez de Herrera, Hernando de Soto y Alonso de Barros, pensadores morales y políticos cuyas voces intervienen en el discurso de las digresiones, A. A. Rodríguez Matos, en cambio, al analizar la narración picaresca $\operatorname{del} G d A$ en cuanto discurso, afirma, pasando al nivel de la digresión, que "en la atalaya se esconde un pícaro" 16

Llama la atencion en las dos Imeas interpretativas la relación directa que se establece entre la condición y la problemática de los cristianos nuevos y la ambigüedad discursiva ${ }^{17}$. Márquez Villanueva, al sostener el carácter laico de las reflexiones reformadoras de Alemán, señala que tanto éste como sus amigos los "arbitristas" Pérez de Herrera, Soto y Barros separaban nítidamente los problemas ético-sociales y filosóficos de los estrictamente religiosos, tal vez por precaución, puesto que cualquier pretensión de proponer una reforma moral en el marco de la religión inmediatamente identificaba a su promotor como "judío", y atraía sobre él la atención del Santo Oficio. La ambigüedad,

${ }^{11}$ Edmond Cros, Ideología y genética textual. El caso del "Buscón", Cupsa, Madrid, 1980, pp. 145-156.

${ }^{12}$ Juditi $\mathrm{A}$. Whrmenack, The impenitent confession of "GdA", Hispanic Seminary of Medieval Studies, Madison, 1985, p. 153.

${ }^{13}$ C. A. Rodríguez Matos, El narrador pícaro: "GdA', Hispanic Seminary of Medieval Studies, Madison, 1985, p. 125.

${ }^{14}$ Nina Cox Davis dice sobre el Guzmán "escritor-convicto": "The synchronic writing of his life is the linguistic burla that aims to achieve a virtually impossible vertical mobility by eternalizing his fame" (Autobiography as "Burla" in the " $G d A$ ", Associeted University Press, Lewisburgh, BucknellLondon-Toronto, 1991, p. 130).

${ }^{15} \mathrm{Y}$ separando de este modo, implícitamente, al narrador, detrás del cual ha de estar directamente el mismo escritor, del personaje, el cual problematiza en sí lo que Alemán arbitrista quisiera corregir en cuanto mal social.

${ }^{16}$ C. A. Rodríguez Matos, op.cit., p. 6.

17 "El GdA es el producto de esta dialéctica personal, que lleva a Alemán, deseoso de justificarse ante el mundo ( $\mathrm{y}$ ante sí mismo) a rebasar su peculiar identidad de cristiano nuevo, para poner de manifiesto, en la persona de Pícaro, al hombre universal que cada cual lleva consigo, sea cual fuere el origen de su cuna" (Maurice Molho, Introducción al pensamiento picaresco, Anaya, Salamanca, 1972, p. 63). 
implantada "en el centro de su obra", sería tal vez el resultado de una estrategia autorial de Alemán ${ }^{18}$. La intención moral así aparece inseparable de una estrategia discursiva dialogizante, pero encubridora.

Desde otro punto de vista, aunque en la misma dirección señala E. Cros la presencia en el discurso penitente de Guzmán de las prácticas discursivas de contrición impuestas como ritos discursivos por la sociedad como "discurso de autoprofanación", en el marco de la relación que el individuo del siglo xVI establecía con la institución inquisitorial. Cros plantea la presencia de la autoprofanación en el discurso del narrador como reproducción del "discurso ajeno"19, esto es, el de la Inquisición, por un Individuo sometido a la represión, de tal modo que la dialogización paródica descrita por Cros evoca un desmembramiento corporal y espiritual del sujeto hablante a modo del carnaval.

Otra marca ideológica dialogizante, relacionada con la anterior, es aquella que tiene que ver con la posición social de la burguesía en el contexto de las presiones y tensiones morales individuales e institucionales, que la sociedad dominada por las axiologías aristocráticas ejercía y provocaba sobre sus integrantes que se ocupaban de los oficios tradicionalmente asociados con los cristianos nuevos. M. Cavillac vincula la emergencia del discurso cuestionador dirigido a los "mercaderes" con el fracaso histórico de la burguesía castellana en la segunda mitad del Xvi ${ }^{20}$. La responsabilidad por la crisis económica que España vive recae entonces sobre la clase de los comerciantes disfrazados en "cambiadores", a quienes la "opinión" estigmatiza por comportarse

${ }^{18}$ F. Márouez Villanueva, "Sobre el lanzamiento...", p. 561.

${ }^{19}$ Edmond Cros, Ideología y genética textual..., p. 156. Cros toma el concepto de "discurso ajeno" de Bajtín-Voloshinov, quienes ponen el problema de "la palabra ajena", "palabra del otro", "discurso referido", en el centro de su concepción del discurso de la novela. Así, la reproducción del discurso del otro se plantea como "dialogización interna de la palabra", como "palabra bivocal" o a dos voces, o bien como el "híbrido sintáctico", porque pone de manifíesto, en el espacio discursivo de un sujeto, varias intenciones, "voces" o discursos encontrados. Cf. Valentín N. Voloshinov, El marxismo y la filosofía del lenguaje, trad. T. Bubnova, Alianza Editorial, Madrid, 1992, pp. 155-209; Mijaíl Bajtín, "La palabra en la novela" [en ruso], en Problemy literatury $i$ estetiki [Problemas de literatura y estética], Judozhestvennaia Literatura, Moscú, 1975, pp. 72-233.

${ }^{20}$ Michel Cavillac, Gueux et marchands dans le "GdA". Roman picaresque et mentalité bourgeoise dans l'Espagne du Siècle d'Or, Institut des Études Ibériques et Ibéro-Americaines de l'Université de Bordeaux, Bordeaux, 1983, pp. 156-158. 
"como hacían los judíos" 21 . Sostenida en la clave de la "historia de las mentalidades", la excelentemente documentada investigación de Gavillac proporciona una buena argumentación histórico-ideológica para explicar el nerviosismo y la polémica interna permanente del discurso de Alemán, burgués e hijo de burgueses, lo mismo que su personaje.

F. Márquez Villanueva descubre el trasfondo burgués y cristiano-nuevo de la ideología de la novela intercalada sobre Bonifacio y Dorotea ${ }^{22}$. En otro trabajo confirma la profunda interacción que existe entre la obra de Alemán y la cervantina. "Cervantes se ha de considerar como el primer relativo admirador y crítico inteligente de aquel nuevo arte de novela"; por otra parte, "se palpa la clarividencia con que el sevillano acogía la obra de Cervantes"'23.

En los trabajos de Márquez Vilianueva, Cros y Cavillac aparecen planteadas, formuladas y comentadas las causas (tensiones ideológicas y morales, discursos sociales dominantes como instrumentos de marginación y represión social) que provocan la dialogización y polemización del discurso del GdA. El desmembramiento de este discurso en voces sociales, que lo cruzan como un territorio de conflicto y crisis, es la propia imagen de la conciencia escindida del narrador pícaro. Estas voces sociales atraviesan dialógica y polémicamente todo el cuerpo discursivo de la novela, tanto la digresión moral como la aventura picaresca, de manera que la unidad textual del $G d A$ consiste en este íntimo desdoblamiento del discurso en las voces sociales, tamizadas por la del narrador.

Resulta, pues, totalmente obsoleto hoy en día dividir sin reservas el texio alemamano en dos discursos supuestamente incompatibles: el de la narración picaresca, cuyo sujeto es Guzmán pícaro, y el de la digresión moralizante, protagonizada por un Guzmán arrepentido y maduro, y en cuya retrospectiva hemos de interpretar la primera. Tal vez una de las dificultades fundamentales del $G d A$ no consista en la divergencia de dos tonos, dos líneas narrativas, dos hipóstasis del personaje, etc., sino que

${ }^{21}$ Ibid., p. 152.

22 F. Márquez Villanueva, "Bonifacio y Dorotea. Mateo Alemán y la novela burguesa", $C H(8)$, t. 1, pp. 59-88.

${ }^{23}$ F. Márquez Villanueva, "La interacción Alemán-Cervantes", Actas del II Congreso Internacional de la Asociación de Cervantistas, Anthropos, Barcelona, 1991, t. 2, pp. 149-181. 
tiene sus raíces en el carácter igualmente dialogizado 24 , que no monológico, de los dos tipos de discurso (aventura-digresión) del libro. Se trata de un dialogismo interior, de una polémica oculta que permea el texto. Mi propósito es el de mostrar de cerca el mecanismo discursivo de esta polémica en el material de los primeros capítulos de la novela, confrontando los resultados con algunos pasajes posteriores en forma más sucinta.

Muchos de los críticos que se ocuparon del análisis del $G d A$ percibieron este íntimo desdoblamiento de voces y de una u otra manera lo señalaron, a veces en contra de sus conclusiones posteriores. F. Rico constata que

... el debate expintual de Guzmin cristaliza con singular withez; pero toda una vida de vaivenes entre el bien y el mal atestigua que en semejante lucha consiste lo más definitorio de su persona. Tal desgarro -en sí mismo o en sus consecuencias- es indudablemente el tema principal del relato...

a propósito del conflicto interior del personaje y sus efectos sobre la narración. Sucede también que esa ruptura íntima del protagonista tiene un "adecuado reflejo estilístico"25. "Es un carácter atormentado y trágico, siempre en lucha consigo mismo', anota A. A. Parker ${ }^{26}$ respecto del personaje. Por cierto, muchos de los críticos que hablaron de la dualidad del GdA la encuentran en la no coincidencia caracterológica entre el narrador y el personaje. F. Rico encabeza la lista de los pocos que apuntan a la proyección de este desdoblamiento sobre el discurso ("estilo").

La autobiografía del pícaro comienza en el nivel del discurso, posponiendo las acciones del relato con respecto a las urgencias del "yo", que se impacienta por manifestarse frente a un "tú" supuestamente atento a la presencia impositiva del sujeto de la enunciación. Es, por una parte, la regla de un juego retórico previamente acordado: el propósito moralizante justifica la emergencia de un aprendiz, aunque éste sea tan sólo una figura virtual:

${ }^{24} \mathrm{El}$ análisis que sigue está basado, en parte, en un viejo artículo mío (escrito en 1978): "El ambiguo discurso de GdA", 'AP, 2 (1980), 161-184.

${ }^{25}$ Francisco Rico, La novela picaresca y el punto de vista, Seix Barral, Barcelona, 1973 , pp. 74-75.

${ }^{26}$ Los picaros en la literatura, Gredos, Madrid, 1971. 
El deseo que tenía, cursioso lector, de contarte mi vida me daba tanta priesa por engolfarte en ella sin prevenir algunas cosas que, como primer principio, es bien dejarlas entendidas... (p. 105) ${ }^{27}$.

Si bien la presencia del tú aquí es impersonal, algo similar al “vuestra merced" del Lazarrillo de Tormes, y aun menos concreta: se trata de un receptor pasivo cuya identidad evanescente es bastante convencional, el yo denso y cargado de tensiones entonacionales desde el principio le impone una situación casi contractual que parece querer involucrar al oyente virtual.

$\mathrm{Y}$ apenas unas líneas más abajo, sin terminar siquiera el periodo, encontramos otro factor, participante de alguna manera tanto de la construcción sintáctica como del tono general de la proposición $y$, por lo tanto, de su sentido:

. . me olvidaba de cerrar un portillo por donde me pudiera entrar acusando cualquier terminista de mal latín, radarguyéndome de pecado, porque no procedí de la definición a lo definido... (p. 105).

La referencia a ese "cualquier terminista"'28 es menos asible todavía a nivel del discurso que la mención del "curioso lector": formalmente el "terminista" no participa ni en la narración (como lo hace el destinatario interno, codificado en un procedimiento retórico) ni en la frase en particular, y, sin embargo, su presencia es más activa que la de este último, porque podemos percibir el eco del discurso del "terminista" en la reacción del narrador, quien justo al entrar en la historia por contar se enfrasca en una especie de discusión indirecta con este ente inasible pero omnipresente, como lo veremos más adelante (reitero que su papel gramatical es pasivo, es objeto al que se refiere el narrador).

La historia que se contará en los primeros dos capítulos de la obra es de por sí bastante sencilla: el protagonista nace de unos padres deshonestos - un caso análogo encaja en sólo dos páginas del Lazarillo-, pero no es fácilmente discernible del variado y nervioso discurso del narrador en el que está aprisionada. Quiere el narrador referir que su padre fue usurero, y la sencilla noticia

${ }^{27}$ Citaré de la ed. de Francisco Rico (cit. supra n. 3); a partir de aquí consignaré el número de página entre paréntesis.

${ }_{28}$ Recordemos que "terminista" podría ser un adepto a "la lógica «moderna" de Guillermo de Ockam, introducida en España con la fundación de la universidad de Alcalá" (F. Rico, ed. cit., p. 105, n. 2). 
crece y se infla con defensas, concesiones y réplicas que se pretende contestar de antemano:

Era su trato el ordinario de aquella tierra [Génova] y lo es ya por nuestros pecados en la nuestra: cambios y recambios por todo el mundo. Hasta en esto lo persiguieron, infamándolo de logrero. Muchas veces lo oyó a sus oídos $[\operatorname{sic}]$ y, con su buena condición, pasaba por ello. No tenían razón, que los cambios han sido y son permitidos. No quiero yo loar, ni Dios lo quiera, que defienda ser lícito lo que algunos dicen, prestar dinero por dinero, sobre prendas de oro y plata, por tiempo limitado o que se queden rematadas, ni otros tratillos paliados, ni los que llaman cambio seco, ni que corra el dinero de feria en feria, donde jamás tuvieron hombre ni trato, que llevan la voz de Jacob y las manos de Esaú y a trio do escopeta descubren el engaño. Que las tales, aunque se las achacaron, yo no las vi ni dellas daré señas.

Mas, lo que absolutamente se entiende cambio es obra indiferente, de que se puede usar bien y mal; y, como tal, aunque injustamente, no me maravillo que, no debiéndola tener por mala, se repruebe (pp. 111-112) $)^{29}$.

En el citado pasaje hay en realidad una gradación de sentidos apreciativos que se van alternando e indican principalmente reprobación o concesión, a saber:

1) "Era su trato el ordinario de aquella tierra y lo es ya por nuestros pecados en la nuestra", apreciación negativa (las cursivas son mías);

2) "Hasta en esto lo persiguieron, infamándolo de logrero", concesión;

3) "No tenían razón: que los cambios han sido y son permitidos", concesión que casi llega a ser afirmación;

4) el inventario bastante completo de clases de cambio y su apreciación moral: " . . a tiro de escopeta descubren el engaño...", negación total;

5) una concesión abrupta: "...lo que absolutamente se entiende cambio es cosa indiferente", etcétera.

Cuando el narrador tiene que decir que su padre fue un hipócrita religioso, hace otra concesión:

${ }^{29}$ He aquí la situación de un "mercader cambista", evocada por Cavillac, que trata de justificar sus actividades, perseguido por una opinión pública adversa. Sin embargo, inmediatamente veremos el doble fondo de tal autodefensa. 
Que un hombre rece, frecuente virtuosos ejercicios, oiga misa, confiese y comulgue a menudo y por ello le llamen hipócrita, no lo puedo sufrir ni hay maldad semejante a ésta (p. 113).

No obstante, la descripción del rosario del padre, "las cuentas más gruesas que avellanas" (p. 113), y de toda su figura rezando ponen en duda la sinceridad de la indignación anterior.

Describe con una especie de humorismo acre al que poco le falta para llegar a sátira, las costumbres religiosas de su progenitor, no cabe duda que con doble intención de desafío al mundo y de ironía respecto a su propia persona, y termina el párrafo con un llamado a los imparciales: "Juzguen deste juicio los que se hallan desapasionados y digan a haya sido perverso y temerario, de gente desalmada, sin conciencia" (p.113).

En seguida, medio paso hacia adelante: "También es verdad que esta murmuración tuvo causa..." (loc cit.), y cuenta la his" toria de la apostasía de su padre, y del matrimonio con una mora rica, historia que no deja lugar a dudas respecto de la calidad moral de aquél, mas: "La proposición es verdadera; pero no hay alguna sin excepción” (p. 114).

Por otra parte, la apostasía era uno de los pecados máximos en la escala moral de la época, pero encontramos una defensa casi violenta:

¿Qué sabe nadie de la manera que toca Dios a cada uno y si, conforme dice una Auténtica, tenía ya reintegradas sus costumbres? (p. 114).

El padre del narrador sí fue, sin lugar a dudas, usurero, hipócrita y renegado: respecto de ese punto el discurso no permite ninguna vacilación. Pero al dar un paso adelante: "cambios y recambios por todo el mundo", da en seguida dos pasos para atrás: "lo que absolutamente se entiende cambio es cosa indiferente, de que se pueda usar bien y mal"'. En realidad, la argumentación no va de la "definición a lo definido", sino al revés: del caso particular bien sabido a una generalización abstracta que borra la responsabilidad inherente a un acto singular realizado por un autor concreto, sustituyéndolo por una "verdad universal", pero anónima.

El esquema general de razonamiento se presenta de la siguiente manera: 
1) el padre sí fue logrero, hipócrita y renegado (premisa mayor);

2) hay indicios según los cuales, además de estos hechos biográficos en sí, había sido una persona desalmada - historia de la apostasía- (premisa menor);

3) "Hermano mío, los indicios no son capaces de castigo por sí solos" (p. 116) (concesión en vez de conclusión).

Hay quienes ven, y no sin razón, una estructura retóricosilogística del discurso en el $G d A$ (E. Cros, F. Rico, C. Blanco); este hecho se afirma inclusive a nivel de la enunciación total: "La autobiografía de Guzmán, en efecto, es un silogismo perfectamente cerrado, de cuyas premisas se infiere sin sombra de duda la consecuenta, Kenerica y personal'30. No obstante, el razonamiento que se acaba de poner de relieve, ¿no sugiere más bien algo parecido a un paradójico antisilogismo, una burla sobre la lógica común? Claro que tal estructura antisilogística, si la hay, sólo puede ser revelada a nivel de los sentidos que afloran con la comparación de las apreciaciones éticas y morales en el discurso del narrador.

Por otra parte, estas respuestas sin preguntas y preguntas que parecen ser retóricas, concesiones y anticipaciones, dan la impresión de formar parte de un diálogo implícito, donde no hay interlocutor expreso permanente, pero sí moral: una especie de presión desde fuera que constantemente provoca la reacción del narrador manifestada por medio de la tensión interior a que ya me he referido.

Creo que no podemos tomar en cuenta, en un intento por reconstruir este supuesto diálogo, al destinatario convencional del relato que es el "curioso lector"; la intención discursiva va dirigida a un cierto personaje, igualmente oculto, que a veces se esconde bajo el indefinido "alguien" ("alguno del arte mercante me dirá"), a veces bajo un pronombre colectivo que está implícito en el verbo ("dirán"), a veces se aproxima al lector virtual, disimula estar detrás de una máscara ("hermano mío"); este ente huidizo a veces pasa a la ofensiva $y$, sin dejarse identificar, ataca: "¿Quién mete al idiota, galeote, pícaro, en establecer leyes ni calificar los tratos que no entiende?" (p. 115), obligando al narrador a defenderse: "Los hombres no son de acero ni están

${ }^{30} \mathrm{~F}$. Rico, "Estructuras y reflejos de estructuras en el $G d A$ ', $M L N, 82$ (1967), p. 174. 
obligados a tener como clavos, que aun a ellos les falta la fuerza y suelen soltar y aflojar" (pp. 114-115).

La manera de actuar discursivamente ${ }^{31}$ que caracteriza al narrador recuerda la anácrisis, procedimiento evocado por Bajtín en su libro sobre Dostoievski, que quiere decir "provocación de la palabra (discurso) por la palabra", y fue recurso utilizado intensamente por el diálogo socrático y la sátira menipea, géneros de la Antigüedad clásica que según el filósofo ruso están en el origen de la novela. "La síncrisis [confrontación de diversos puntos de vista sobre un tema determinado] y la anácrisis dialogizan el pensamiento, lo exteriorizan convirtiéndolo en répli$c a^{3132}$, dice Bajtín al comentar el efecto de este procedimiento sobre el discurso literario. En el proceso de la dialogizacion interna, el cuestionamierto latente en la percepción de mi discurso por el otro tiene el impacto especular por reflejo, anticipando la respuesta del interlocutor dentro de mi propia elocución.

En el GdA, los personajes verdaderos (explícitos) participan poco en el diálogo, sobre todo en un intercambio de posiciones ideológicas. Se puede hablar, sin embargo, de los personajes (destinatarios o interlocutores) implícitos (uno o varios), que hablan con el narrador a través de su autoconciencia, siendo codificada de este modo su presencia en el discurso del narrador. Ahora bien, la diferencia cardinal entre el destinatario interno y el interlocutor implícito está en el hecho de que el papel del primero es puramente formal o retórico, siempre y cuando detrás

31 Desde aquí, introduzco la idea de acto ético (en ruso, postipok) a la concepción de la comunicación discursiva, que procede de la filosofía bajtiniana (c). Myjaíl Bajtín, $K$ filosofii postupja [Hacia una filosofía del acto ético, h. 1924], ed. e introd. S. Bocharov, en Filosofiia $i$ sotsiologiia nauki i tejniki [anuario 1984-85], Nauka, Moscú, 1986, pp. 80-161). El mundo en que actúa el individuo es, según Bajtín, el espacio de aplicación de los actos éticos, es decir, de todos los actos ejecutados ante la presencia y para el otro, bajo la permanente mirada del otro que evalúa y da sentido a cuanto hago yo. Así, todos los actos humanos tienen el rango ético y representan el acontecimiento que deviene entre dos, en presencia del "tercero", cuya valoración rebasa aquella que proporciona el otro. Así, hay actos cotidianos y cognoscitivos, actos pensamiento y actos enunciado, y todos ellos forman parte de una dimensión ética, gracias a la responsabilidad/responsividad personal que les es inherente: en el ser no hay coartada, sino un permanente involucramiento y responsabilidad para con el otro. El acto siempre se produce como respuesta a la presencia valorativa del otro de la que dependemos, por lo tanto siempre es réplica y respuesta.

32 Mujaíl Bajtín, Problemas de la poética de Dostoievski (1963), trad. T. Bubnova, F.C.E., México, 1986, p. 157. 
de él no esté el segundo; a su vez, la presencia del interlocutor implícito, identificado o no con el destinatario interno, se verifica por la resonancia que deja en el discurso del narrador. Por otra parte, la autoconciencia del narrador puede identificarse con el interlocutor implícito (nunca con el destinatario interno como tal); por ejemplo, el enunciado “¿Quién mete al idiota, galeote, pícaro, en establecer leyes, etc.?" puede interpretarse como un reflejo de la autoconciencia, puesto que la condición de galeote del narrador es asumida por él mismo (aunque por primera vez la revela el autor en la "Declaración para el entendimiento deste libro", por cierto). Pero tal tipo de autoconciencia sólo puede ser impulsada desde el exterior, por la condición social del narrador $y$, por lo tanto, ha de wincularse, de alguna manera, con el merlocutor mplícito en su faceta le representante de la sociedad. De hecho, este discurso rellejo remite al "discurso de la represión" evocado por $\mathbb{E}$. Cros (cf. supra).

El discurso del narrador a menudo tiene esta intención pluriorientada hasta en sus elementos menores: " ... el mío [padre] y sus deudos fueron levantiscos" (p. 111). "Levantisco" en lugar de "levantino", sugiere una ascendencia de conversos ${ }^{33}$; es una provocación latente en vista del desarrollo posterior del relato que describe la devoción del padre de Guzmán. Gili y Gaya comenta que en Alemán el vocablo evoca otro significado: "el que se levanta o se alza con algo"34, en relación con el episodio ulterior de la mora. El doble significado de la palabra nos remite a lo que sucede en la historia del padre, dos veces levantisco, por su ascendencia y por su actuación, pero: "Qué sabe nadie de la manera que toca Dios a cada uno?" Así que en este caso tenemos una autoprovocación, una autocalificación como siguiente paso (Guzmán se sabe hijo de un levantisco), y una autoconcesión o absolución como paso concluyente: otra vez un antisilogismo o una paradoja. La triple orientación es obvia: una toma de conciencia de sí mismo por parte del personaje, un desafío al interlocutor, y el propio desarrollo del relato, al que a su vez es imposible desligar de una doble orientación ética: hacia el sujeto y hacia el exterior. Es por algo que B. Brancaforte, al hablar de la confesión guzmaniana, se acuerda del "hombre del subsuelo", quien escribe "para sí mismo", pero desafía al posible inter-

33 B. Brancaforte, ed cit, t. 1, p. 105, n. 37.

34 Guzmán de Alfarache, ed. S. Gili y Gaya, Espasa-Calpe, Madrid, 1926, t. $1, \mathrm{p} .49$. 
locutor que, supuestamente, jamás lo escuchará; se denigra a sí mismo, pero cifra su rescate en el otro, por medio de esta "escapatoria" (ruso lazeika; ingl. loophole) ingeniosa ${ }^{35}$.

De esta manera, bastante complicada, se teje este discurso en el que lo esencial consiste en bajo qué aspecto, en qué luz, se presenta lo narrado.

Si siguiéramos la tradición de los dos Guzmanes divergentes estilísticamente, aunque unidos bajo un punto de vista único (el del moralismo cristiano), cabría suponer que la historia picaresca debería caracterizarse por una sintaxis más enérgica, menos complicada y arreglada, menos estructurada formalmente, más, por así decirlo, entrecortada en comparación con las digresiones morates, las cuales, según indicaba A. A. Parker, lo mismo que E. Cros, están emparentadas con el sermón eclesiástico de la época. Pueden hallarse ejemplos que confirmen tal suposición; tomemos uno correspondiente al pleno desarrollo de la historia, parte $1^{a}$, libro II, capítulo 1: "Vesme aquí en Cazalla, doce leguas de Sevilla, lunes de mañana, la bolsa apurada y con ella la paciencia, sin remedio y acusado ladrón en profecía”' (p. 247). Los deícticos y locativos, el tiempo verbal, la similicadencia, la misma sintaxis enérgica remiten a la orientación hacia un relato hablado.

En seguida, una digresión:

Con esto he visto lo poco que se contenta nuestra madre naturaleza. y por mucho que a todos dé, ninguno está contento: todos viven pobres publicando necesidad. Oh, epicúreo, desbaratado, pródigo, que locamente dices comer tantos millares de ducados de renta! Di que los tienes y no que los comes. Y si los comes, ¿de qué te quejas, pues no eres más hombre que yo, a quien podridas lentejas, cocosas habas, duro garbanzo y arratonado bizcocho tienen gordo? ¿No me dirás o darás la razón que lo cause? Yo no la sé (p. 248).

Esta invectiva supuestamente la profiere un Guzmán instalado en las galeras, desde su posición de convicto, en contraste con el primer ejemplo, en que Guzmán aparece inmerso en su circunstancia pasada. En efecto, se nota más el tono coloquial de la historia picaresca, en tanto que la digresión discursiva que

${ }^{35}$ Cf. el análisis de las Memorias del subsuelo de Dostoievski por BAJTín (Problemas de la ..., pp. 320-333). ¿Qué mejor "subsuelo" que las "galeras de la vida" de Alemán, desde donde habla su héroe? 
encarna el "presente" de la escritura es un periodo retórico de mayor elaboración sintáctica que incluye paralelismos, preguntas retóricas, cláusulas concesivas, etc. No obstante, la tensión coloquial en el sentido de cierta materialización de un interlocutor retórico, está presente aquí también.

En realidad, las digresiones siempre aparecen contaminadas de tono coloquial. He aquí el desarrollo retórico de una:
$\mathrm{Al}$ amancebado le consumieron el tiempo y la mala mujer; al juga- dor desengañó el tablajero que, como sanguisuela de unos y otros, poco a poco les va chupando la sangre: hoy ganas, mañana pier- des, rueda el dinero, vásele quedando y los que juegan, sin él; al famoso ladrón reformaron el miedo y la vergüenza; al temerario murmurador, la perlesía, de que pocos escapan; al soberbio su misma miseria lo desengaña, conociéndose que es lodo; al mentiro- so puso freno la mala voz y afrentas que de ordinario recibe en sus mismas barbas; al desatinado blasfemo corrigieron continuas reprehensiones de sus amigos y deudos... (pp. 116-117).

Y su conclusión: “. . . al entrar en la gloria, dirán los ángeles unos a otros llenos de alegría: "Laetamini in Domino. ¿Escribano en el cielo? Fruta nueva, fruta nueva». Con esto acabó su sermón. Que hayan vuelto al escribano, pase"' (pp. 117-118). El periodo acaba por contaminarse de dialogismo coloquial.

La historia picaresca contiene elementos de una confesión desgarradora y de una polémica interior de doble orientación (moralidad y desafío); las digresiones adquieren características coloquiales y también se dialogizan internamente. Además, la concatenación de los diferentes "estilos" en un mismo periodo establece un nuevo tipo de relación dialógica interna: un diálogo intratextual. La particularidad fundamental de este discurso en dos planos es un bivocalismo implícito, un concierto de voces con múltiple orientación por medio de la cual se obtiene el efecto de esa tensión y nerviosismo internos del estilo del $G d A$ advertidos por la crítica. Al mismo tiempo, ya en el primer capítulo se puede percibir cómo encauza el autor las aparentes desavenencias de tono para conseguir el efecto de una conclusión unívoca (moraleja cristiana), y también se ve que en el monologismo exterior de la moraleja se abre una considerable brecha: el capítulo termina con la historia del monstruo de Ravena, símbolo de la depravación del género humano que, sin embargo, lleva en sí signos de la futura salvación divina. Aquí tampoco falta esta polémica 
ambigua; el narrador no deja de orientarse hacia afuera y de lanzar réplicas a su(s) interlocutor(es) implícito(s), ni de hacer concesiones a su propia persona al descargar una parte de culpa a su padre:

Ves aquí, en caso negado, que, cuando todo corra turbio, iba mi padre con el hilo de la gente y no fue solo el que pecó. Harto más digno de culpa serías tú, si pecases, por la mejor escuela que has tenido. Ténganos Dios en su mano para no caer en otras semejantes miserias que todos somos hombres (p. 124).

En el segundo capítulo la actitud del narrador hacia lo narrado es un poco distinta. Se está contando la historia de nacimien. to de Guzmán, de la cual resulca que es un bastardo; antes de que se le haga notar por otros, el narrador se adelanta y se lanza al ataque; la actitud general que se aprecia en este capítulo en comparación con el anterior, es un grado mucho mayor de exhibicionismo cínico:

Sea como fuere y el levantisco, mi padre; que pues ellos lo dijeron y cada uno por sí lo averaba, no es bien que yo apele las partes conformes. Por suyo me llamo, por tal me tengo, pues de aquella melonada quedé legitimado con el santo matrimonio, y estáme muy mejor, antes que diga un cualquiera que soy malnacido y hijo de ninguno (pp. 140-141).

Es decir, en medio del alarde por su confusa ascendencia, el narrador expone de antemano todas las críticas que podrían hacérsele.

Es cierto que Guzmán constantemente se distrae de la narración del suceso puro de la historia para pasar a una moralización generalizadora; pero a menudo se sorprende en la intención de sermonear de la cual no se considera digno:

¡Oh qué gentil disparate! ¿Qué fundado en Teología! ¿No veis el salto que he dado del banco a la popa? ¿Qué vida de San Juan de Dios la mía para dar esta dotrina! Calentóse el horno y salieron las llamaradas. Podrásme perdonar por haber sido corto (p. 139).

$\mathrm{Y}$ en seguida sale con otro sermón: "No mires a quien lo dice, sino a lo que se te dice" (loc. cit.). Y por cierto, tanto en el pasaje acabado de citar, el hecho de remitir al momento de la 
escritura en las galeras, como un poco más adelante: "Vuelvo a mi puesto, que me espera mi madre, ya viuda del primero poseedor, querida y tiernamente regalada del segundo" (loc. cit.), muestran un sabor precervantino (como en el episodio del vizcaíno, Quijote, I, 9) en la conciencia de la convencionalidad de la distancia entre el momento de la acción y el de la escritura ${ }^{36}$.

El narrador del $G d A$ siempre tiene la conciencia de ser personaje tal como aparece en la historia, hecho que garantiza la compatibilidad entre estas dos categorías narrativas. La autoconciencia, el saberse mirado por otros, constituye una de las características más importantes de la imagen de Guzmán, la que contribuye en profundidad y verosimilitud a su capcioso discurso. Este desgarro interion fue amphamente comentado por $F$. Rico inclusive a nivel de la historia, si salimos del marco restrictivo de los capítulos iniciales de la novela. Guzmán sabe, por ejemplo, que actúa mal en el episodio con el agnusdei del capitán que lo llevaría a Génova, está consciente de que les quita el pan a los verdaderos pobres e indigentes haciendo de mendigo en Roma, sabe exactamente quién es al prostituir a Gracia su mujer, etc. Es evidente que Guzmán no es una figura concebida unidimensionalmente, bajo el signo pecado-arrepentimiento: hay demasiada malicia en lo uno y en lo otro; sin este constante desdoblamiento entre el bien y el mal, entre la agresividad y la autodefensa, entre el desafío y el sermón, sin esta continua tensión entre la particularidad del hecho aislado y su inscripción en el significado de una moral absoluta Guzmán no existiría como imagen artística. Más aún: la escisión entre un acto concreto y su inscripción permanente en la ética consuetudinaria o formal diluye la responsabilidad concreta por su proceder en el embriagamiento discursivo del cual el narrador se da cuenta. En él, junto con su maldad, está presente la conciencia de la misma, y no sólo como un arrepentimiento devoto, sino también como una constante "mirada hacia el otro", hacia el exterior: agresividad, resentimiento, autodefensa, el miedo y la exposición deliberada al ridículo. Todo ello encuentra una adecuada expresión a nivel del discurso, en la permanente discusión consigo mismo y con el mundo: Guzmán se

36 Por otra parte, y ya que de la confrontación con Cervantes se trata, nótese que tanto la murmuración como la contrarréplica mencionadas arriba anticipan los papeles de Berganza y Cipión en el Coloquio de los perros, obra, como bien se ha demostrado, que es en sí una réplica al concepto de la picaresca alemaniana. 
está condenando, Guzmán se está justificando, Guzmán quiere permanecer como es: "Pues ni quiero mandos ni dignidades, no quiero tener honra ni verla; estáte como te estás, Gruzmán amigo..." (p. 275).

Las digresiones sobre la honra pueden considerarse como una de las más claras manifestaciones de la autoconciencia a nivel del discurso:

Que diz que ha de estar sujeta mi honra de la boca del descomedido y de la mano del atrevido el uno porque dijo y el otro porque hizo lo que fuerzas ni poder humano pudieran resistirlo. ¿Qué frenesí de Satanás casó este mal abuso con el hombre, que tan desatinado lo tiene? (p. 261).

Para los fines estrictamente formales de este estudio no es necesario pasar al nivel ideológico para demostrar la presencia de la dialogización interna del discurso y de la autoconciencia.

Ahora bien, tanto el narrador como el personaje poseen una autoconciencia con funciones bastante complejas; además, el discurso del yo narrativo en el $G d A$ absorbe y pone de relieve el del interlocutor implícito; de una manera general, el discurso del narrador refleja el del otro, que puede funcionar ora como autoconciencia, ora como discurso de interlocutor implícito, a veces identificado con el destinatario interno, formal, del relato. A nivel del texto, la autoconciencia aparece como una orientación deĺ discurso hacia el sujeto, como ya he señalado. Tal orientación presupone varias instancias éticas y actitudes emocionales que he intentado aclarar arriba. En el caso del $G d A$, el sujeto de la enunciación (el autor) se identifica a veces con el narrador; hablando en términos del diálogo entre el sujeto que habla y su autoconciencia, dentro de la realidad construida, podemos introducir el concepto del doble, a veces paródico. Recordando a Julia Kristeva, se podría decir que "el diálogo no es la «libertad" de decirlo todo: es una "burla» (Lautréamont) pero trágica, un imperativo distinto del Uno"37. Recuérdese al respecto el "antisilogismo", que se ha mencionado en el curso del análisis del discurso alemaniano.

El criterio dialogístico podría transferirse a otros niveles, por ejemplo al ya mencionado nivel intratextual, sin referencia a los

37 Julla KRisteva, El texto de la novela, trad. J. Llovet, Lumen, Barcelona, 1974 , p. 127. 
contextos, fuentes ni relaciones entre los géneros, confrontando los diferentes "estilos" en la narración o relacionando el discurso con los textos de las novelas intercaladas. Por ejemplo, B. Brancaforte apunta hacia la dialogización de la parodia que hace Alemán del "carácter novelístico del Guzmán apócrifo"38, el de Mateo Luján. En este caso, el diálogo interno tiene por objetivo a un destinatario externo de segundo grado: otro libro.

Así, pues, en el $G d A$ se perciben varias voces, varias voluntades que he tratado de definir en términos de un análisis narrativo, sin excluir el nivel axiológico, que producen un efecto de diálogo interior, de una polémica constante en distintos niveles (el del discurso, el de la ideología, el de la estructuración total), y, por lo tanto, no apuntan hacia un solo sentido de la obra, sino hacia una polisemia, una plurvalencia que estructura a una nor simplex natura. GdA sigue dejando una sensación de inconformidad, de desorden, de provocación, al no querer caber del todo en el estrecho molde de una moraleja, por sublime que sea.

La unidad del $G d A$ no remite a un enfoque único de varios desarrollos narrativos exteriormente disparejos, sino que se funda en un dialogismo interno propio de todos ellos en igual medida. La autoconciencia, la escapatoria discursiva basada en la valoración del yo por el otro, y el doble paródico son los recursos discursivos de la ambivalencia dialogizante. Con base en un análisis formal de este tipo, que acaba por plantear posiciones de responsabilidad, estamos en el umbral de un examen de los actos discursivos en cuanto actos éticos ${ }^{39}$.

Tatiana Bubnova Universidad Nacional Autónoma de México

${ }^{38}$ Ed. cit., t. 1, p. 59.

39 Tomando en cuenta que "la ética no es fuente de los valores, sino el modo de relacionarse con los valores"' (cf. Mujaíl Bajtín, Problemas de la..., p. 81). 